\title{
INFLUÊNCIA DA EMBALAGEM NO DESENVOLVIMENTO DE INJÚRIAS MECÂNICAS EM TOMATES ${ }^{1}$
}

\author{
Larissa Rodrigues de CASTRO², \\ Luís Augusto Barbosa CORTEZ2, * , José Tadeu JORGE²
}

\begin{abstract}
RESUMO
Avaliou-se cinco tipos de embalagens (duas plásticas, duas de papelão ondulado e a caixa K de madeira) quanto à proteção fornecida ao tomate variedade Santa Clara durante seu transporte e manuseio. Os tomates acondicionados em tais embalagens foram comparados com frutos controle, isto é, aqueles que não sofreram qualquer tipo de vibração, impacto ou choque, de acordo com a porcentagem daqueles contendo injúrias mecânicas e segundo também sua intensidade. Os tomates foram armazenados à temperatura ambiente por 7 dias, até atingirem $100 \%$ de coloração vermelha, e avaliados quanto à incidência de deterioração, perda de peso e sabor (analiticamente através da relação Brix/acidez titulável e por análise sensorial). Os resultados mostraram que os tomates localizados na parte inferior das caixas foram os mais prejudicados e que as ripas de madeira, ásperas e distantes entre si, assim como os pregos da caixa $\mathrm{K}$, foram responsáveis pelos danos mais significativos. As avaliações apontaram a embalagem de papelão ondulado de menor tamanho como a de maior proteção contra injúrias mecânicas nos tomates.
\end{abstract}

Palavras-chave: tomate; embalagem; manuseio pós-colheita; injúria mecânica.

\section{SUMMARY}

PACKAGING INFLUENCE ON THE DEVELOPMENT OF MECHANICAL INJURIES IN TOMATOES. Five different packages (2 made of plastic, 2 of cardboard, and 1 made of wood) were evaluated with respect to the protection of tomatoes (Santa Clara variety) during their transportation and handling. These tomatoes were compared to control samples, as related to fruits with no physical impact or vibration, considering the percentage of those fruits with mechanical injuries and their severity. The fruits were stored at ambient temperature for 7 days until they reached full-color and then evaluated regarding the incidence of decay, weight loss, and flavor by Brix/acidity ratio and sensory analysis. The results have shown that the tomatoes on the bottom of the boxes had worse bruises and that the separated clapboards and the clues of wooden boxes caused the most severe injuries. The results also permitted the conclusion that there were less bruised tomatoes in the smaller cardboard package compared to the plastic and wooden boxes.

Keywords: tomato; packages; postharvest handling; mechanical injury.

\section{1 - INTRODUÇÃO}

O tomate é um produto de grande relevância nutricional e econômica. Dentre os produtos hortifrutícolas,

\footnotetext{
${ }_{1}^{1}$ Recebido para publicação em 29/12/99. Aceito para publicação em 30/11/00.

2 UNICAMP, Faculdade de Engenharia Agrícola - Depto. Construções Rurais. Caixa Postal 6011, CEP 13083-970, Cidade Universitária "Zeferino Vaz" $s / n$, Campinas, SP. larissarcastro@softhome.net

* A quem a correspondência deve ser enviada.
}

ele se destaca representando $23 \%$ de todo o volume comercializado no Entreposto Terminal de São Paulo CEAGESP [4]. Em nível mundial, GAYET et al [6], citam que dentre as hortaliças, o tomate registra o segundo maior volume de produção/consumo, sendo precedido pela batata e um pouco à frente da alface, com volume duas vezes maior que o da cebola. Segundo COSTA \& CAIXETA FILHO [5], tomando-se um grupo de dez vitaminas e minerais, o tomate é o décimo sexto em concentração desses nutrientes, mas constitui o primeiro em sua contribuição na dieta brasileira, por ser consumido com grande freqüência e em geral na forma crua (evitando-se a cocção e conseqüente perda de nutrientes).

De acordo com dados de COSTA \& CAIXETA FILHO [5], as perdas registradas para tal produto variam muito entre as Regiões brasileiras. Na cidade de São Paulo, a estimativa foi de cerca de $12 \%$ de perdas em 1991 e 1992, enquanto que em Minas Gerais tal índice atingiu aproximadamente $40 \%$ em 1990 . Tais perdas são decorrentes, principalmente, de fatores como: faIhas na fase de produção; colheita fora de época; danos mecânicos; embalagem; manuseio e transporte inadequados; tempo de exposição prolongado em nível de varejo; hábitos prejudiciais de seleção por parte do consumidor; preços desfavoráveis pagos ao produtor e falta de orientação de mercado.

Dentre os fatores citados, SINGH, SINGH, BATHEJA [13], mostram que a operação do empacotamento é uma das que mais influenciam a qualidade da fruta in natura durante o transporte e distribuição, até chegar ao consumidor. Segundo BORDIN [2], a importância das embalagens reside no fato de que são as responsáveis por conter e proteger o produto hortícola contra as adversidades do meio de distribuição, de modo a tornar mais conveniente e eficaz o seu manuseio e comercialização.

Dentre as embalagens para tomates, MADI [8] cita que as caixas $\mathrm{K}$, inicialmente projetadas para conter latas de querosene e atualmente amplamente utilizadas para produtos hortifrutícolas, possui vários inconvenientes, dentre os quais pode-se citar: a baixa qualidade da madeira provoca constantes colapsos da embalagem, causando sérias perdas de produto; são pesadas e de superfícies ásperas dificultando o manuseio e provocando injúrias nos frutos. NANTES [10] também cita que, pelo fato da altura da caixa K ser $61,97 \%$ maior que sua largura, ocorre a formação de várias camadas de tomates, aumentando a pressão exercida pelos frutos superiores sobre os inferiores. COSTA \& 
CAIXETA FILHO [5], recomendam as embalagens de papelão ondulado para o tomate, por reduzirem as perdas, permitindo que um volume maior de produto esteja apto à comercialização. Em comparação com a caixa de madeira (caixa "K"), embora as feitas com papelão apresentem valor unitário maior (custo), estas não possuem o inconveniente da proliferação de patógenos, como ocorre com as caixas de madeira normalmente reutilizadas sem nenhum tipo de limpeza. Muitas empresas e mesmo institutos de pesquisa e universidades norte-americanas apontam as caixas plásticas como a tendência mundial, pois, de acordo com BORDIN [2], apesar de possuírem molde específico de custo elevado, estas embalagens oferecem inúmeras vantagens que vão desde a alta resistência e durabilidade, até a possibilidade de higienização, desmontagem e reutilização.

Conforme ASHRAE [1], os cuidados pós-colheita envolvem, dentre outros, o empilhamento das embalagens de maneira adequada à ventilação possibilitando um resfriamento rápido. $O$ efeito provocado pelo manejo envolvendo embalagens de alta rugosidade, e portanto abrasivas, é cumulativo. Vários ferimentos pequenos em um tomate podem produzir uma perda de sabor. Os danos mecânicos provocam aumento na perda de umidade. Segundo NANTES [10], esses ferimentos podem ser agravados pelas condições ambientais, tendo-se ao final um efeito somatório levando o produto a perder qualidade.

MAUL [9] mostra, por exemplo, que abusos na póscolheita, como fruta colhida ainda imatura, injúrias mecânicas durante a classificação e a operação de empacotamento, transporte à temperaturas inadequadas, são relatados por alterar os componentes voláteis de aroma e a percepção do sabor. Conforme descrito em INSTITUTO ADOLFO LUTZ [7], a determinação da acidez é necessária, por fornecer um importante dado na avaliação do estado de conservação de um produto alimentício.

De acordo com SARGENT [11], após a colheita, as hortaliças perdem firmeza devido aos processos de desenvolvimento, senescência e perda de água. Como resultado, tornam-se mais susceptíveis às injúrias mecânicas. Os tomates são muito sensíveis a injúrias internas, que se tornam aparentes após o tomate atingir o estádio de completo amadurecimento (coloração vermelha). Tais injúrias se desenvolvem quando um fruto recebe um impacto sobre o lóculo durante a colheita ou manuseio. O impacto altera o desenvolvimento no gel locular e, no estádio de amadurecimento completo, o gel é opaco e verde-amarelado ao invés de ter uma coloração clara e vermelha. $O$ tomate é mais sensível a choques, principalmente após o início da etapa de amadurecimento; assim, uma queda de $10 \mathrm{~cm}$ é suficiente para causar descoloração interna de até $73 \%$ dos frutos nesta etapa (com até $10 \%$ de coloração vermelha), enquanto que apenas $5 \%$ dos frutos ainda verdes apresentariam tal injúria.

SOARES et al [14] também mostram que os frutos menos maduros são mais firmes e, portanto, mais resistentes às injúrias mecânicas durante o manuseio e o transporte. Também descrevem que as injúrias enfraquecem ou destróem as defesas naturais do tomate, sua cera natural e "pele", criando condições para o desenvolvimento de fungos e bactérias. As injúrias mecânicas agem como uma porta de entrada para microrganismos, que provocam infecção, podendo se proliferar e contaminar frutos próximos e de boa qualidade.

De acordo com SARGENT, BRECHT, ZOELLNER [12], os tomates transportados a longas distâncias estão, freqüentemente, sob condições que podem promover o crescimento de organismos deteriorantes nos locais de injúrias mecânicas (como ferimentos por impacto e compressão, cortes e abrasões). Sendo as injúrias mecânicas cumulativas, as várias etapas do manuseio, do campo ao consumidor, devem ser cuidadosamente coordenados e integrados para minimizar as perdas na qualidade do produto. Embora a injúria interna não seja normalmente detectável em packinghouses, pode ser percebida pelo consumidor e sua presença poderá comprometer compras subseqüentes.

Esta pesquisa pretende analisar embalagens plásticas de polietileno, de papelão ondulado e de madeira de pinus (caixa K) quanto à proteção fornecida a tomates contra injúrias mecânicas, durante seu transporte e manuseio. Os resultados permitirão selecionar e desenvolver, futuramente, embalagens que promovam uma proteção mais eficiente ao produto, que serão então usadas em experimentos futuros para serem avaliadas quanto à possibilidade de promover uma circulação adequada de ar em seu interior, permitindo o resfriamento rápido de toda a carga.

\section{2 - MATERIAL E MÉTODOS}

\section{1 - Matéria-Prima}

Os tomates (variedade Santa Clara) foram colhidos em uma propriedade da empresa Milani localizada entre os municípios de Elias Fausto e Indaiatuba, SP. A temperatura ambiente no dia da colheita variou de 22 a $26^{\circ} \mathrm{C}$, enquanto que a temperatura dos frutos, no momento em que foram colhidos, era de aproximadamente $21^{\circ} \mathrm{C}$. Os tomates foram colhidos das 8 às 11 horas da manhã, colocados em cestas de "vime" e então transferidos para caixas $\mathrm{K}$ (de madeira pinus), no galpão de classificação. Neste, os frutos foram despejados em mesas para a seleção daqueles a serem usados nos experimentos, escolhendo-se apenas os tomates livres de qualquer injúria mecânica, inseto ou doença. Quanto ao estádio de maturidade, foram selecionados frutos apresentando de $1 \%$ a $60 \%$ de coloração vermelha e então colocados nas embalagens estudadas (conforme especificadas nas Tabelas 1 e 2 e Figura 1), enquanto que alguns permaneceram em 3 caixas $\mathrm{K}$ para fins de comparação. Vinte frutos foram colocados em bandejas de papelão com separação individual para evitar qualquer vibração, impacto ou compressão mecânica durante seu transporte, constituindo o grupo controle segundo SINGH, SINGH, BATHEJA [13], SARGENT, BRECHT, ZOELLNER [12]. As embalagens foram dis- 
postas, aleatoriamente, no veículo (caminhonete F 1000), mas procurando submetê-las às mesmas condições de transporte, quanto à carga a ser suportada, exposição à radiação solar/umidade e posição em relação à roda (fator que pode influenciar nos impactos de vibração). As amostras controle foram transportadas dentro da cabine de passageiros a fim de se evitar, ao máximo, qualquer injúria mecânica nos frutos. O percurso compreendeu cerca de $75 \mathrm{~km}$ em estrada asfaltada (Indaiatuba - Elias Fausto - Campinas) em más condições de conservação. Também se andou por aproximadamente $10 \mathrm{~km}$ em estrada de terra (da propriedade rural à rodovia).

TABELA 1. Dimensões externas das embalagens utilizadas

\begin{tabular}{ccc}
\hline Embalagens & Peso líquido da caixa (kg) & $\begin{array}{r}\text { Dimensões externas (mm) } \\
\text { (comprimento, largura, altu) }\end{array}$ \\
\hline $\begin{array}{l}\text { Caixa plástica de } \\
\text { polietileno maior }\end{array}$ & 2,144 & $560 \times 360 \times 310$ \\
$\begin{array}{l}\text { Caixa plástica de } \\
\text { polietileno menor }\end{array}$ & 1,500 & $600 \times 400 \times 190$ \\
$\begin{array}{l}\text { Caixa de papelão } \\
\text { ondulado maior }\end{array}$ & 0,962 & $600 \times 400 \times 155$ \\
Caixa de papelão & & $487 \times 277 \times 148$ \\
ondulado menor & 0,490 & \\
\end{tabular}

TABELA 2. Especificações das embalagens de papelão ondulado utilizadas

\begin{tabular}{|c|c|c|}
\hline $\begin{array}{l}\text { Embalagens de papelão } \\
\text { ondulado/ Especificações }\end{array}$ & Caixa maior & Caixa menor \\
\hline Gramatura $\left(\mathrm{g} / \mathrm{m}^{2}\right)$ & 990 & $\begin{array}{c}500 \text { nas folhas e } 300 \text { nas } \\
\text { ondas }\end{array}$ \\
\hline Grau de material reciclado & $100 \%$ fibras virgens & $\begin{array}{c}\text { Capas externa e } \\
\text { intermediária em fibra } \\
\text { virgem e capa interna com } \\
\text { tratamento hidro-repelente }\end{array}$ \\
\hline Resistência à compressão (kg) & 270 & 450 \\
\hline Mullen $\left(\mathrm{kg} / \mathrm{cm}^{2}\right)$ & 21,0 & * \\
\hline
\end{tabular}

* Como esta caixa tem duas ondas e apresenta uma alta resistência à perfuração, a empresa fabricante não considerou o teste de Mullen necessário.

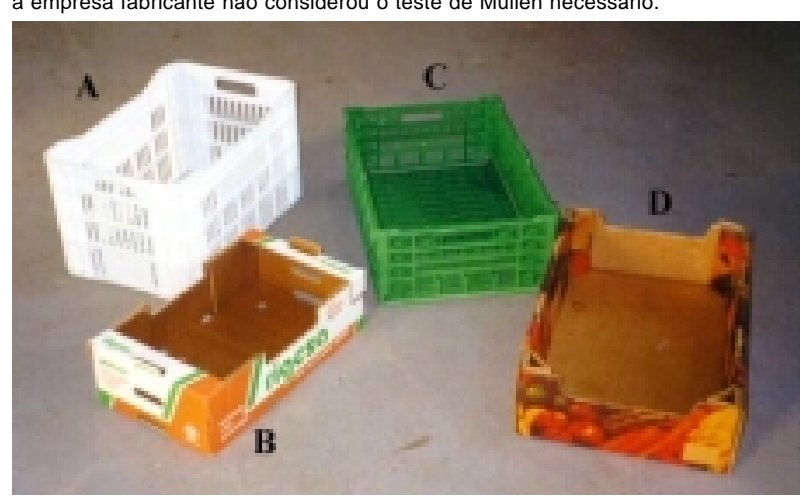

FIGURA 1. Caixa plástica maior (A), caixa de papelão ondulado menor (B), caixa plástica menor (C), caixa de papelão maior (D)

\section{2 - Armazenagem}

Os frutos foram armazenados à temperatura ambiente durante 7 dias (média de $22^{\circ} \mathrm{C}$ ao longo do experimento), ou seja, até atingirem $100 \%$ de coloração vermelha e textura de "amolecidos". A temperatura foi monitorada por um sistema de aquisição de dados por computador, composto por: um microcomputador IBM/ PC compatível, contendo uma placa de condicionamento de sinais analógicos PCX-0802 e um conversor de sinais CAD-12/32, com 32 canais de aquisição; termopares tipo "T"; software AQDADOS para transformar os sinais de $\mathrm{mV}$ em graus Celsius (toma-se como referência a temperatura da junta fria medida pelo CAD 12/32). O programa de aquisição foi ajustado para leitura das temperaturas a cada quinze minutos, em 8 termopares inseridos no interior das embalagens e do produto.

\section{3 - Porcentagem de frutos contendo injúrias mecânicas}

Ao chegar no Laboratório de Termodinâmica e Energia, da Faculdade de Engenharia Agrícola/UNICAMP, cada caixa foi esvaziada e todos os seus frutos avaliados quanto à existência de ferimentos e sua gravidade, tendo-se em vista a profundidade e área superficial do produto (registrada em função da maior dimensão) atingidas ( $<10 \mathrm{~mm}$, de 10 a $20 \mathrm{~mm}$ e $>20 \mathrm{~mm})$. Para tal medição, utilizou-se um paquímetro digital Digimatic Caliper, code n 500-171, model CD-6"C, Mitutoyo Corporation, Japan. Os resultados foram expressos em porcentagem de frutos encontrados em cada nível de injúrias.

\section{4 - Massa, diâmetros longitudinal e transversal e estádio de maturidade}

No mesmo dia da colheita, foram utilizados cerca de $10 \%$ dos frutos de cada caixa, isto é, 15 tomates de cada caixa $\mathrm{K}$, plástica, e papelão de maior porte, 10 tomates da embalagem de papelão menor e 6 frutos controle, para as análises de massa, diâmetros longitudinal e transversal e estádio de maturidade (dado pela coloração). Tais medições foram realizadas em cada fruto, individualmente, obtendo-se, posteriormente, o valor médio. O peso foi obtido através de uma balança fabricada pela empresa Marte Balanças e Equipamentos, modelo AS 1000C, com 0,0g de precisão e $1000 \mathrm{~g}$ de carga máxima. Os diâmetros longitudinal e transversal foram medidos utilizando-se o mesmo paquímetro já descrito. A coloração média de cada fruto foi determinada visualmente através de uma escala de porcentagens de coloração vermelha (de 0 a $100 \%$ ).

\section{5 - Análises de $\mathrm{pH}$, sólidos solúveis totais e acidez titulável total}

Realizou-se análises de $\mathrm{pH}$, sólidos solúveis totais (Brix) e acidez titulável total dos tomates um dia após a colheita e depois de 7 dias de armazenagem, utilizando-se 5 frutos de cada caixa (unidade experimental) enquanto que se utilizou apenas 3 frutos do controle, triturados separadamente. Para tais medições con- 
tou-se com as recomendações de CARVALHO et al [3], a saber:

\section{- Sólidos solúveis totais (Brix)}

Utilizou-se um refratômetro digital, Abbe Refractometer, modelo 2WAJ, Shanghai Optical Instrument Company (Hong Kong).

\section{- $\quad \mathbf{p H}$}

Foi determinado pelo método eletrométrico. $O$ potenciômetro usado nos experimentos foi o "Microprocessor Bench-top HI 8417, Hanna Instruments, Italy".

\section{- Acidez titulável total}

Utilizou-se o método onde a acidez é fornecida em $\mathrm{g}$ de ácido cítrico/100ml ou $100 \mathrm{~g}$ de suco. Calculou-se também a relação Brix/acidez titulável total.

\section{6 - Perda de peso}

Mediu-se a variação média de massa $\left(P_{\text {inicial }}-P_{\text {final }} /\right.$ $\left.P_{\text {inicial }}\right)$ de 5 frutos de cada caixa e 3 do controle, mantendo-se os mesmos tomates ao longo do experimento. $O$ peso final correspondeu àquele obtido após 7 dias de armazenagem.

\section{7 - Porcentagem de frutos com incidência de po- dridão}

Ao final dos 7 dias de armazenagem foram contados os tomates de cada caixa que apresentavam qualquer tipo de deterioração, em relação ao número total de frutos contidos em cada embalagem, anotando-se a gravidade do problema segundo o mesmo critério usado para os ferimentos ou injúrias mecânicas dos tomates (isto é, tendo-se em vista a profundidade e área superficial, registrada em função da maior dimensão do produto, atingidas, com as seguintes classificações: $<10 \mathrm{~mm}$, de 10 a $20 \mathrm{~mm}$ e $>20 \mathrm{~mm}$ ). Para tal medição foi utilizado o paquímetro digital já especificado.

\section{8 - Análise sensorial}

Ao final da armazenagem (após atingido 100\% de coloração vermelha), os frutos foram avaliados por 10 provadores quanto à diferença de sabor entre a amostra controle e os tomates das demais embalagens. Cada provador teve que experimentar primeiramente 1 fruto controle para então compará-lo a mais 6 tomates: 1 fruto de cada tipo de embalagem (vide Tabela 1), mais 1 fruto da caixa K e 1 controle "escondido". Este último se refere a um tomate do grupo controle, ou seja, também livre de qualquer injúria mecânica que foi inserido na amostragem dada aos provadores para verificar, propositadamente, se os mesmos conseguiriam identificar alguma semelhança ou diferença entre ele, o outro fruto controle provado e aqueles com injúrias. Os frutos analisados foram servidos em bandejas aos provadores e contendo uma etiqueta com os códigos referentes às embalagens estudadas. Cada provador recebeu uma ficha para avaliar o sabor dos tomates de acordo com uma escala não estruturada de $10 \mathrm{~cm}$, onde a distância do zero correspondeu à diferença entre os frutos analisados, ou seja:

0 - indicando não haver diferença alguma entre a amostra controle e o fruto testado

10 - amostras analisadas completamente diferentes do controle

$\mathrm{Na}$ ficha existia um espaço para observações julgadas necessárias pelo provador.

\section{9 - Análise estatística}

O delineamento estatístico empregado foi o inteiramente casualizado, com 3 repetições, exceto para a análise sensorial, onde foi usado o delineamento em blocos casualizados, com 10 blocos. Para comparação entre as médias utilizou-se o Teste Tukey.

\section{3 - RESULTADOS E DISCUSSÃO}

A seguir são mostrados todos os valores medidos e calculados para o experimento, no dia em que se realizou a colheita e após 7 dias de armazenagem. Nas Tabelas, letras iguais indicam não haver diferença entre os tratamentos (embalagens), segundo o Teste Tukey a $5 \%$ de significância.

TABELA 3. Massa, diâmetros longitudinal e transversal e estádio de maturidade (\% de coloração vermelha) no dia da coIheita e transporte ao laboratório

\begin{tabular}{|c|c|c|c|c|}
\hline $\begin{array}{c}\text { Tipo de } \\
\text { Embalagem }\end{array}$ & Massa (g) & $\begin{array}{c}\text { Diâmetro } \\
\text { longitudinal } \\
(\mathrm{mm})\end{array}$ & $\begin{array}{c}\text { Diâmetro } \\
\text { transversal } \\
(\mathrm{mm})\end{array}$ & $\begin{array}{r}\text { Estádio de } \\
\text { maturidade ( } \\
\text { de coloraçã } \\
\text { vermelha) }\end{array}$ \\
\hline $\begin{array}{c}\text { Caixa de } \\
\text { papelão maior }\end{array}$ & $212,31 \mathrm{a}$ & $72,85 \mathrm{a}$ & $72,14 \mathrm{a}$ & $52,22 \mathrm{a}$ \\
\hline Caixa K & 206,24 a & $72,55 \mathrm{a}$ & $70,88 \mathrm{a}$ & 44,89 a \\
\hline $\begin{array}{c}\text { Caixa de } \\
\text { papelão menor }\end{array}$ & $221,08 \mathrm{a}$ & $71,54 \mathrm{ab}$ & $70,90 \mathrm{a}$ & $46,33 \mathrm{a}$ \\
\hline $\begin{array}{c}\text { Caixa plástica } \\
\text { menor }\end{array}$ & 202,92 a & $71,12 \mathrm{ab}$ & $71,32 \mathrm{a}$ & 53,78 a \\
\hline $\begin{array}{c}\text { Caixa plástica } \\
\text { maior }\end{array}$ & $215,42 \mathrm{a}$ & $70,83 \mathrm{ab}$ & $70,02 \mathrm{a}$ & $51,11 \mathrm{a}$ \\
\hline Controle & $183,22 \mathrm{a}$ & $66,92 \mathrm{~b}$ & 65,87 a & 46,67 a \\
\hline
\end{tabular}

Os resultados mostram não existir diferença significativa, a 5\% de significância, para os diâmetros longitudinais médios no dia da colheita entre todas as caixas estudadas (exceto os frutos controle), e entre as embalagens plásticas e a de papelão ondulado de menor porte com relação ao controle. Também nota-se que os tomates das caixas de papelão maior e caixa $\mathrm{K}$ possuíam diâmetro longitudinal maior que àqueles do controle.

Como se pode observar pela Tabela 3, os frutos utilizados na pesquisa apresentavam massas, diâmetros transversais e maturidades médias equivalentes a $5 \%$ de significância. 
TABELA 4. Porcentagem média de frutos contendo injúrias inferiores a $10 \mathrm{~mm}$ de 10 a $20 \mathrm{~mm}$, superiores a $20 \mathrm{~mm}$, e independente de sua gravidade (total), no dia da colheita e transporte ao laboratório

\begin{tabular}{ccccc}
\hline Tratamentos & $\begin{array}{c}\text { Inferiores a } \\
10 \mathrm{~mm}\end{array}$ & De $10 \mathrm{a} 20 \mathrm{~mm}$ & $\begin{array}{c}\text { Superiores a } \\
20 \mathrm{~mm}\end{array}$ & Total \\
\hline Caixa K & $6,81 \mathrm{~b}$ & $57,92 \mathrm{a}$ & $31,87 \mathrm{ab}$ & $96,60 \mathrm{a}$ \\
Zaixa plástica menor & $16,07 \mathrm{ab}$ & $41,69 \mathrm{bc}$ & $38,35 \mathrm{a}$ & $96,11 \mathrm{a}$ \\
Caixa de papelão & $21,30 \mathrm{a}$ & $47,72 \mathrm{ab}$ & $23,34 \mathrm{ab}$ & $92,35 \mathrm{a}$ \\
$\quad$ maior & & & & \\
Caixa plástica maior & $17,52 \mathrm{ab}$ & $29,57 \mathrm{c}$ & $39,69 \mathrm{a}$ & $86,78 \mathrm{a}$ \\
Caixa de papelão & $25,04 \mathrm{a}$ & $13,92 \mathrm{~d}$ & $15,55 \mathrm{~b}$ & $54,51 \mathrm{~b}$ \\
$\quad$ & & & \\
\hline menor & & & & \\
\hline
\end{tabular}

Pelos resultados mostrados na Tabela 4 observase que não houve diferença significativa, a $5 \%$ de significância, entre os valores de porcentagem média de frutos com injúrias mecânicas inferiores a $10 \mathrm{~mm}$, encontrados para as embalagens de papelão ondulado e de plástico, assim como entre as caixas plásticas e a de madeira (caixa K). Entretanto, as caixas de papelão apresentaram maior porcentagem de frutos com injúrias inferiores a $10 \mathrm{~mm}$ que a caixa $\mathrm{K}$.

Nota-se que não existiu diferença a $5 \%$ de significância entre os valores de porcentagem média de frutos com injúrias mecânicas de 10 a 20mm encontrados para a caixa $\mathrm{K}$ e a de papelão ondulado de maior porte, para esta última e a embalagem plástica menor, e desta com relação à caixa plástica maior. A embalagem de papelão ondulado menor provocou menores valores de injúrias mecânicas de 10 a 20mm comparados às demais.

Os resultados também mostram que não ocorreu qualquer diferença a 5\% de significância entre os valores de porcentagem média de frutos com injúrias mecânicas superiores a $20 \mathrm{~mm}$ encontrados para a caixa $\mathrm{K}$ e a de papelão ondulado de maior porte e as caixas plásticas, assim como entre as embalagens de papelão ondulado e a caixa K. No entanto, as caixas plásticas apresentaram maior porcentagem de frutos com injúrias superiores a $20 \mathrm{~mm}$ que a caixa de papelão de menor porte.

Ainda, pela Tabela 4 pode-se concluir que a porcentagem de frutos contendo injúrias mecânicas nas caixas de papelão ondulado de menor porte foram inferiores às demais embalagens, a $5 \%$ de significância. Tais resultados podem ser explicados por se tratar de uma embalagem com capacidade de apenas $10 \mathrm{~kg}$, que continha no máximo 2 camadas de tomates, e, portanto os frutos da base sofreram uma carga de compressão inferior àqueles das demais embalagens. Esses resultados, assemelham-se, de certa forma, aos observados por SINGH, SINGH, BATHEJA [13], que encontraram menor firmeza para as amostras de caixas com $47 \mathrm{~cm}$ de profundidade comparadas às amostras daquelas com $14 \mathrm{~cm}$. Os autores perceberam que a incidência de deterioração também estava relacionada à profundidade das camadas de fruto, além de variar com a duração do processo de vibração e do período de armazenagem. NANTES [10] também estudou o nível de injúrias formadas nos tomates Santa Clara submetidos ao transporte em estrada asfaltada de $80 \mathrm{~km}$, dependo da embalagem utilizada no acondicionamento. $\mathrm{O}$ autor observou valores semelhantes aos encontrados nesta pesquisa, obtendo, após 3 dias de armazenagem a $25,1^{\circ} \mathrm{C}$ aproximadamente $93,76 \%$ dos tomates da caixa $\mathrm{K}$ com algum tipo de lesão e $90,75 \%$ para os tomates da caixa plástica com as seguintes dimensões $(500 \times 320 \times 220) \mathrm{mm}$.

Um fator que pode ter agravado a formação de danos nos frutos é o modo como foram manuseados desde a colheita. Da etapa em que foram colhidos e colocados dentro da cesta de vime até serem despejados na mesa de classificação e então empacotados, os tomates sofreram uma série de efeitos de impacto, choque e vibração. Não apenas as embalagens utilizadas no experimento, como também esses fatores citados devem ser levados em consideração na análise das injúrias mecânicas observadas nos frutos. Embora tenha havido uma seleção dos frutos sem qualquer tipo de injúria para serem utilizados na pesquisa, vale ressaltar que injúrias internas não podem ser identificadas quando o fruto ainda não está com $100 \%$ de coloração vermeIha, podendo então ter sido escolhidos tomates já injuriados no campo para o experimento.

De modo geral, as injúrias observadas no experimento foram em sua maior parte do tipo "corte" e abrasões nos frutos das caixas plásticas e "amassados" naquelas de papelão ondulado. Um fator que pode ter influenciado os resultados obtidos, quanto à incidência e gravidade de injúrias mecânicas, é o maior manuseio dos tomates pertencentes às embalagens plásticas e de papelão. Isto é, para serem preenchidas, primeiramente foram completadas algumas caixas $\mathrm{K}$, para só então tais tomates serem transferidos para as caixas definitivas (plásticas e de papelão), enquanto que no caso das 3 caixas $\mathrm{K}$ estudadas, estas foram preenchidas diretamente, sem haver nenhuma transferência de qualquer outra embalagem. Isto pode ter agravado os ferimentos observados naqueles frutos.

As injúrias mais graves estavam presentes nos tomates das caixas $\mathrm{K}$, devido a superfície extremamente áspera da madeira e seus nós, além dos inúmeros pregos que contribuem para provocar as injúrias mais graves e profundas. Os tomates mais prejudicados foram aqueles localizados na base da caixa sofrerem a maior carga de compressão, principalmente nos frutos acomodados entre as ripas de madeira. Segundo NANTES [10], a existência de frestas nas laterais e na união desta com a base da caixa $\mathrm{K}$, além de não permitirem ventilação adequada, são irregulares e funcionam como lâminas para os frutos acondicionados nestas posições. O autor também relata que essa situação é agravada pela aspereza da madeira, que em contato direto com o epicarpo dos frutos, leva ao aparecimento de injúrias mecânicas. Os frutos situados no topo das caixas $\mathrm{K}$ também tiveram sérios problemas de amassamento. 
Isto porque, segundo MADI [8], devido à alta resistência mecânica da madeira, o produtor em geral ultrapassa a capacidade máxima da caixa $\mathrm{K}$, comprimindo a tampa contra os frutos. $O$ autor também relata que os produtores consideram que caixas não preenchidas além da sua capacidade máxima provocam maiores danos no tomate devido à excessiva vibração dos frutos durante o transporte. Para o transporte num percurso de $100 \mathrm{~km}$ em estrada asfaltada, MADI [8] observou que preenchendo a caixa $\mathrm{K}$ com tomates até sua capacidade máxima obteve-se $26 \%$ de frutos danificados comparados a $36 \%$ de perdas de produto nas embalagens que ultrapassaram esta marca, enquanto foi encontrada uma perda média de apenas $16 \%$ de tomate nas caixas de papelão ondulado.

SOARES et al [14] estudaram a influência da utilização de embalagens de madeira (caixas K) na conservação da qualidade do tomate e também observaram que todos os tomates em contato com as aberturas entre as ripas das caixas "K" apresentaram sérios problemas com injúrias mecânicas, especialmente cortes e amassados, que poderiam ser reduzidas significativamente com a utilização de caixas de papelão. MADI [8] citou que segundo as normas para a caixa $\mathrm{K}$, deveriam ser deixados $2 \mathrm{~cm}$ de espaçamento entre as ripas de madeira da tampa, mas que esse valor é freqüentemente maior e como as caixas são preenchidas além da sua capacidade os frutos sofrem compressão e cortes quando a caixa é tampada.

Nas caixas plásticas as ranhuras e aberturas, essencialmente da base, influenciaram os resultados, provocando um efeito como de um "carimbo", deixando marcas profundas nos tomates estudados. Neste caso, o mais recomendado seriam as caixas plásticas de fundos lisos ou embalagens de papelão ondulado.

Além dos frutos localizados na base das caixas, aqueles situados nas laterais, principalmente em contato com as alças das embalagens, sofreram cortes e abrasões graves. SOARES et al [14] também perceberam que a posição do fruto dentro da caixa influencia a intensidade da injúria mecânica. Os tomates que se encontravam em contato com a tampa, laterais ou base foram os que sofreram mais abrasões (47\% a mais) que aqueles localizados no meio da caixa, ou seja, sem contato direto com as lâminas de madeira ásperas. O excesso de tomates dentro da caixa provocou significativos danos, na ordem de 10 a $20 \mathrm{~mm}$ por fruta.

Não foi verificada qualquer diferença significativa entre a porcentagem média de frutos com podridão inferior a $10 \mathrm{~mm}$ para as diferentes embalagens estudadas após 7 dias de armazenagem, com $5 \%$ de significância.

Os resultados mostraram que após 7 dias de armazenagem não ocorreu diferença a $5 \%$ de significância entre a porcentagem média de frutos com podridão de 10 a $20 \mathrm{~mm}$ obtida para a caixa $\mathrm{K}$ e a plástica de menor porte, assim como entre esta última e as outras embalagens. No entanto, a caixa $\mathrm{K}$ apresentou maior por- centagem de frutos com podridão de 10 a $20 \mathrm{~mm}$ que as embalagens de papelão e plástica de maior porte.

TABELA 5. Porcentagem média de frutos contendo incidência de podridão inferior a $10 \mathrm{~mm}$, de 10 a $20 \mathrm{~mm}$, superior a $20 \mathrm{~mm}$, e independente de sua gravidade (total), após 7 dias de armazenagem

\begin{tabular}{ccccc}
\hline Tratamentos & $\begin{array}{c}\text { Inferiores a } \\
10 \mathrm{~mm}\end{array}$ & De $10 \mathrm{a} 20 \mathrm{~mm}$ & $\begin{array}{c}\text { Superiores a } \\
20 \mathrm{~mm}\end{array}$ & Total \\
\hline Caixa K & $7,48 \mathrm{a}$ & $11,22 \mathrm{a}$ & $7,10 \mathrm{a}$ & 25,80 \\
Caixa plástica menor & $3,77 \mathrm{a}$ & $6,22 \mathrm{ab}$ & $7,37 \mathrm{a}$ & $17,36 \mathrm{c}$ \\
Caixa plástica maior & $2,39 \mathrm{a}$ & $4,03 \mathrm{~b}$ & $6,96 \mathrm{a}$ & $13,38 \mathrm{c}$ \\
$\begin{array}{c}\text { Caixa de papelão } \\
\text { maior }\end{array}$ & $1,23 \mathrm{a}$ & $4,08 \mathrm{~b}$ & $3,91 \mathrm{a}$ & $9,22 \mathrm{k}$ \\
$\begin{array}{c}\text { Caixa de papelão } \\
\text { menor }\end{array}$ & $1,45 \mathrm{a}$ & $2,90 \mathrm{~b}$ & $1,42 \mathrm{a}$ & $5,77 \mathrm{t}$ \\
\hline
\end{tabular}

Não se observou qualquer diferença significativa entre a porcentagem média de frutos com podridão superior a $20 \mathrm{~mm}$ para as diferentes embalagens pesquisadas após 7 dias de armazenagem, a 5\% de significância.

Os valores encontrados na Tabela 5 afirmam não existir diferença a $5 \%$ de significância entre os valores de porcentagem média de frutos com podridão de qualquer gravidade para a caixa $\mathrm{K}$ e as caixas plásticas, assim como para estas últimas e aquelas feitas de papelão ondulado. No entanto, a caixa K apresentou maior porcentagem de frutos com podridão que as embalagens de papelão.

Observa-se que os resultados de porcentagem de frutos com incidência de podridão não foram muito expressivos, quando comparados, por exemplo, com àqueles encontrados por SOARES et al [14], que obtiveram uma média de cerca de 44\% após 6 dias de armazenagem. No entanto, os valores encontrados na pesquisa demonstraram que, por exemplo para a caixa $\mathrm{K}$, quase $26 \%$ dos frutos não apresentam qualquer condição de qualidade aceitável para sua comercialização, sem contar com aqueles mostrados na Tabela 4 que apresentavam qualquer tipo de injúria mecânica. Isto representa uma perda muito grande, o que pode diminuir a margem de lucro de comercialização do tomate ou elevar o preço final pago pelo consumidor. Como possíveis soluções para reduzir tais números se poderia citar a realização de sanitização e uma classificação dos frutos. Não houve nenhuma preocupação em estabelecer uma padronização dos frutos que iriam em cada embalagem, mas vale lembrar que a seleção e classificação reduz injúrias mecânicas, uma vez que tomates com maior uniformidade de tamanho e formato, se acomodam melhor dentro das caixas, diminuindo as possibilidades de ferimentos com vibração, impacto ou choque.

Os resultados da Tabela 6 mostram que não há diferença significativa para os valores iniciais da relação 'Brix/acidez média entre as caixas plásticas, de papelão ondulado e a embalagem de madeira, assim como 
entre a plástica de menor porte, as de papelão ondulado, caixa $\mathrm{K}$ e frutos controle. No entanto, os frutos da caixa plástica maior apresentaram relação ${ }^{\circ}$ Brix/acidez superior aos do controle.

TABELA 6. Relação ${ }^{\circ}$ Brix/acidez média para os frutos no dia da colheita e transporte ao laboratório e após 7 dias de armazenagem

\begin{tabular}{ccc}
\hline Tratamentos & $\begin{array}{c}{ }^{\circ} \text { Brix/acidez no dia da } \\
\text { colheita }\end{array}$ & $\begin{array}{c}{ }^{\circ} \text { Brix/acidez após 7 dias de } \\
\text { armazenagem }\end{array}$ \\
\hline Caixa de papelão maior & $15,7 \mathrm{ab}$ & $15,6 \mathrm{a}$ \\
Caixa K & $14,4 \mathrm{ab}$ & $15,1 \mathrm{a}$ \\
Caixa plástica maior & $16,2 \mathrm{a}$ & $15,1 \mathrm{a}$ \\
Caixa de papelão menor & $15,8 \mathrm{ab}$ & $15,1 \mathrm{a}$ \\
Controle & $12,8 \mathrm{~b}$ & $14,8 \mathrm{a}$ \\
Caixa plástica menor & $14,5 \mathrm{ab}$ & $14,3 \mathrm{a}$
\end{tabular}

Analisando-se ainda a Tabela 6 não se observou qualquer diferença significativa entre os valores da relação ${ }^{\circ}$ Brix/acidez para os frutos das diferentes embalagens pesquisadas após 7 dias de armazenagem, a $5 \%$ de significância.

Observou-se que não houve qualquer diferença significativa para o $\mathrm{pH}$ médio dos tomates, tanto antes (se manteve na média de 4,39) e após a armazenagem (média 4,36), entre as diferentes embalagens pesquisadas, a $5 \%$ de significância.

NANTES [10] também observou diferenças pequenas na acidez titulável, sólidos solúveis totais e $\mathrm{pH}$ entre os tomates das caixas plásticas e de madeira ( $\mathrm{K} \mathrm{e}$ $\mathrm{M})$. Após 6 dias de armazenagem a $22^{\circ} \mathrm{C}$, o autor também obteve valores da relação ${ }^{\circ}$ Brix/acidez de cerca de 14,5 e de $\mathrm{pH}$ de aproximadamente 4,29.

Não se observou qualquer diferença significativa para a perda de peso média após 7 dias de armazenagem entre as diferentes embalagens pesquisadas (aproximadamente $2,51 \%$ ), a $5 \%$ de significância, pois estas não apresentaram barreira diferenciada aos vapores de água. Mas, pode-se dizer que a perda de peso média para todas as embalagens estudadas foi inferior àquela obtida por NANTES [10], que encontrou aproximadamente $4,47 \%$ para tomates Santa Clara submetidos ao transporte em estrada asfaltada de $80 \mathrm{~km}$, acondicionados em caixas plásticas e na caixa de madeira $\mathrm{M} \mathrm{e}$ armazenados por 6 dias a $22^{\circ} \mathrm{C}$.

TABELA 7. Análise sensorial média após 7 dias de armazenagem

\begin{tabular}{cc}
\hline Tratamentos & Médias \\
\hline Caixa de papelão menor & $5,3 \mathrm{a}$ \\
Caixa de papelão maior & $5,1 \mathrm{ab}$ \\
Caixa plástica menor & $3,1 \mathrm{ab}$ \\
Caixa plástica maior & $2,7 \mathrm{ab}$ \\
Caixa K & $2,6 \mathrm{~b}$ \\
Controle (escondido) & $2,6 \mathrm{~b}$ \\
\hline
\end{tabular}

Através dos resultados encontrados na análise sensorial, segundo a Tabela 7 , pode-se observar que os provadores não identificaram diferença de sabor, a $5 \%$ de significância, entre os frutos do controle e de todas as embalagens estudadas, exceto a caixa de papelão menor. Segundo os provadores, os tomates desta última embalagem apresentaram sabor diferente daquele encontrado na caixa $\mathrm{K}$ e no controle.

Analisando-se os resultados das Tabelas anteriores percebe-se que as embalagens de papelão ondulado foram aquelas que, de modo geral, melhor protegeram os tomates, produzindo menores valores de injúrias mecânicas. Os dados da análise sensorial não confirmaram tais resultados, provavelmente devido à falta de treinamento dos provadores, pois estes podem ter usado a preferência pessoal como fator determinante na avaliação e não propriamente a comparação (semelhança/diferença) com os frutos controle.

\section{4 - CONCLUSÕES}

Pelos resultados obtidos e análises visuais efetuadas pôde-se observar que as caixas plásticas provocam injúrias em sua maior parte na forma de abrasões e cortes enquanto que, as de papelão ondulado causam fortes amassados devido sua superfície mais lisa e plana. Os frutos de maiores ferimentos foram aqueles que se encontravam na base e laterais por sofrerem uma maior carga de compressão.

Embora não se tenha verificado diferenças significativas entre os tipos de embalagens para a maioria dos itens analisados, a caixa de papelão de menor porte se mostrou a que gerou menores valores para a porcentagem total de frutos injuriados, indicando uma maior proteção aos tomates durante o transporte e manuseio devido provavelmente a sua capacidade de carga inferior.

A caixa $\mathrm{K}$ em específico, foi a que exerceu menor proteção aos tomates, observado pelas maiores porcentagens de frutos com injúrias mecânicas e podridão. Suas tábuas de madeira áspera, nós e pregos poderão ter sido os fatores de maior influência na formação de injúrias graves nos tomates, principalmente naqueles que se acomodavam no espaço entre as ripas.

\section{5 - REFERÊNCIAS BIBLIOGRÁFICAS}

[1] ASHRAE. Refrigeration Systems and Applications Handbook. Atlanta, 1994. Cap. 17: Vegetables. p.1-14.

[2] BORDIN, M. R. Embalagem para Frutas e Hortaliças. In: Curso de Atualização em Tecnologia de Resfriamento de Frutas e Hortaliças, 2. Campinas, Faculdade de Engenharia Agrícola, UNICAMP, 1998. p.19-27.

[3] CARVALHO, C. R. L.; MANTOVANI, D. M. B.; CARVALHO, P. R. N.; MORAES, R. M. Análises Químicas de Alimentos (Manual Técnico). Campinas, Biblioteca do ITAL, 1990.

[4] CEAGESP, Secretaria de Agricultura e Abastecimento, Governo do Estado de São Paulo. Classificação de tomate. Programa Horti\&Fruti - Programa Paulista para meIhoria dos Padrões Comerciais e Embalagens de Hortigranjeiros, 1998. (folheto) 
[5] COSTA, F. G.; CAIXETA FILHO, J. V. Análise das Perdas na Comercialização de Tomate: um estudo de caso. São Paulo: [s.n.], 1996. 26p.

[6] GAYET, J. P.; BLEINROTH, E. W.; MATALLO, M.; GARCIA, E. E. C.; GARCIA, A. E.; ARDITO, E. F. G.; BORDIN, M. R. Tomate para Exportação: Procedimentos de Colheita e Pós-colheita. Ministério da Agricultura, do Abastecimento e da Reforma Agrária, Secretaria do Desenvolvimento Rural, Programa de Apoio à Produção e Exportação de Frutas, Hortaliças, Flores e Plantas Ornamentais - Brasília: EMBRAPA-SPI, 1995. 34p. Série Publicações Técnicas FRUPEX; 13.

[7] INSTITUTO ADOLFO LUTZ. Normas Analíticas, Métodos Químicos e Físicos para Análises de Alimentos. 3.ed. São Paulo: Instituto Adolfo Lutz, 1985. 371p.

[8] MADI, L. F. C. Comparison between the existing package (caixa K) and new transport packages for fresh tomatoes in Brazil. East Lansing, 1977. 56p. M. Sc. Dissertation. Michigan State University.

[9] MAUL, F. Recommended Storage Temperatures Affect Tomato Flavor and Aroma Quality. Gainesville, 1999. M. Sc. Dissertation. Horticultural Sciences Department, University of Florida.

[10] NANTES, J. F. D. Protótipos de caixas plásticas para acondicionamento, transporte e armazenamento de tomates.
Jaboticabal, 1998. 91p.Tese de doutorado. Faculdade de Ciências Agrárias e Veterinárias, Universidade Estadual Paulista Julio de Mesquita Filho (UNESP).

[11] SARGENT, S. A. Handling and Cooling Techniques for Maintaining Postharvest Quality. In: HOCHMUTH, G. J., MAYNARD, D. N. Vegetable Production Guide for Florida. Gainesville: University of Florida, 1998. Chapter 17.

[12] SARGENT, S. A.; BRECHT, J. K.; ZOELLNER, J. J. Sensitivity of Tomatoes at Mature-green and Breaker Ripeness Stages to Internal Bruising. Journal of the American Society for Horticultural Science, Alexandria, v.117, n.1, p.119123, 1992.

[13] SINGH, A.; SINGH, Y.; BATHEJA, S. Suitability of Packaging Boxes for Tomatoes. Journal of Food Science and Technology, v.29, n.6, p.381-383, 1992.

[14] SOARES, A. G.; CORRÊA, T. B. S.; SARGENT, S. A.; ROBBS, C. F. Perdas na Qualidade de Tomate na Cadeia Produtiva, Rio de Janeiro, EMBRAPA, 1993.

\section{6 - AGRADECIMENTOS}

À Fundação de Auxílio à Pesquisa do Estado de São Paulo (FAPESP) pela bolsa de mestrado concedida e pelo apoio financeiro à pesquisa. 